\title{
The Transit-Oriented Development (TOD) Index and Its Application to Metro Stations in Bangkok
}

Author(s): Srisamrit Supaprasert, Manoj Lohatepanont, Krisana Visamitanan

Source: Journal of International Logistics and Trade 2021; 19(3):115-131

Published by: Jungseok Research Institute of International Logistics and Trade, Inha University

DOI: https://doi.org/10.24006/jilt.2021.19.3.115

Journal of International Logistics and Trade is an official journal published by Jungseok Research Institute of International Logistics and Trade, Inha University, Korea. JILT welcomes manuscripts that advance the practice and science of logistics, trade, and other related fields.

Frequency: Quarterly (March, June, September, December)

Stable URL: https://www.ejilt.org

Jungseok Research Institute of International Logistics and Trade is a specialized academic research institute representing Inha University and Inha Foundation in Korea. The institute aims to become a representative institute in Northeast Asia in the research of logistics and trade.

Stable URL: https://jrieng.inha.ac.kr

(C) Copyright. Jungseok Research Institute of International Logistics and Trade.

This is an Open-Access article distributed under the terms of the Creative Commons Attribution NonCommercial License (http://creativecommons.org/licenses/by-nc/4.0/) which permits unrestricted noncommercial use, distribution, and reproduction in any medium, provided the original work is properly cited 



\title{
Journal of International Logistics and Trade
}

J. Int. Logist. Trade, 2021, Vol. 19, No. 3, 115-131

pISSN : 1738-2122 eISSN : 2508-7592

https://doi.org/10.24006/jilt.2021.19.3.115

https://www.ejilt.org

\section{ARTICLE}

\section{The Transit-Oriented Development (TOD) Index and Its Application to Metro Stations in Bangkok}

\author{
Srisamrit Supaprasert ${ }^{1}$, Manoj Lohatepanont ${ }^{2,}{ }^{*}$, Krisana Visamitanan $^{3}$ \\ ${ }^{1}$ Graduate School, Chula Logistics and Supply Chain Management Program, Bangkok, Thailand \\ ${ }^{2}$ Transportation Institute, Chulalongkorn University, Bangkok, Thailand \\ ${ }^{3}$ Chulalongkorn Business School, Chulalongkorn University, Bangkok, Thailand
}

Received June 14, 2021
Revised July 1, 2021
Accepted July 29, 2021

*Corresponding author: Manoj Lohatepanont
Transportation Institute, Chulalongkorn
University, Bangkok, Thailand
Tel: +66-97-043-7116
E-mail: Manoj.L@chula.ac.th

\begin{abstract}
Studies on the Transit-Oriented Development (TOD) for Bangkok are found sparingly. The TOD concept is a supportive development for the rapidly changing city in order to reduce urban transport problems while encouraging people to shift transport modes to use public transportations instead of private cars. This study discusses the context of TOD in the density, the design, and the diversity of land use around transit stations among successful stations in many countries. There were 18 station areas in Bangkok which, by using the TOD Readiness score, the assessment of the stations implies that the higher scoring transit stations are more compatible to supporting pedestrian use of the transit station with lower car dependency. The 4 top-scoring stations were assessing by using multinomial logistic regression model. The study has found TOD scores and the frequent uses of the stations consequently encourage the commuters around the station areas decided to rely on public transport instead of car dependency. This is an effort to overcome the understanding of the station areas by reducing the complexity of the TOD contexts to any transit station in Thailand to be eligible for future study.
\end{abstract}

Keywords Transit-Oriented Development, Multinomial logistic regression

\section{Introduction}

Each day in Bangkok, the need for mass rapid transit has been increasing. Meanwhile there will always be people experiencing minor problems related to urban transportation and the issue tends to increase along with the growing city population. These problems are considered an obstacle to reducing the use of private transportations such as car uses, which may result in failure to encourage people to change behavior and switch to using public transport instead of driving (Higgins and Kanaroglou 2016). The achievement of transport mode shifting is a result of both the development at the station and the ability of public transit created by the development of transit-orientation (Lund and Wilson 2005). A concept called TransitOriented Development (TOD) that considers using policy intervention as a solution to the aforementioned challenges (Boschmann and Brady 2013), especially when promoting a model for urban design and planning in areas around transit stations (Vale 2015). The TOD is a concept of city development which is integrated with the development of transportation infrastructure, especially for focus in the areas around important transit stations. TOD motivates people to use public transit instead of private vehicles (Widyahari and Indradjati 2015).

Bangkok aims to stimulate a modal shift from cars to public transport, and the city environment is appropriate for TOD, however it was found that there have been no studies on criteria for the development of transit orientation, which are able to identify and evaluate the station area in order to understand the station typology. Recently, the growing number of cars used, along with the urbanism movement in Bangkok, creates frustration with traffic congestion and sprawl. Therefore, the TOD concept must become a great recognition of the advantages of consolidating policy development and transition to the city growth and transportation networks. Since the TOD application in Bangkok is found sparingly, the goal of this study is to bring the TOD Readiness Index up to scale in terms of being applicable for everyone to ensure accessibility to basic services, affordable transportation and walkability. For this reason, it is a must to describe a vision of TOD that is suitable to Bangkok's contexts and that establishes a TOD assessment that is forethought and realistic. 


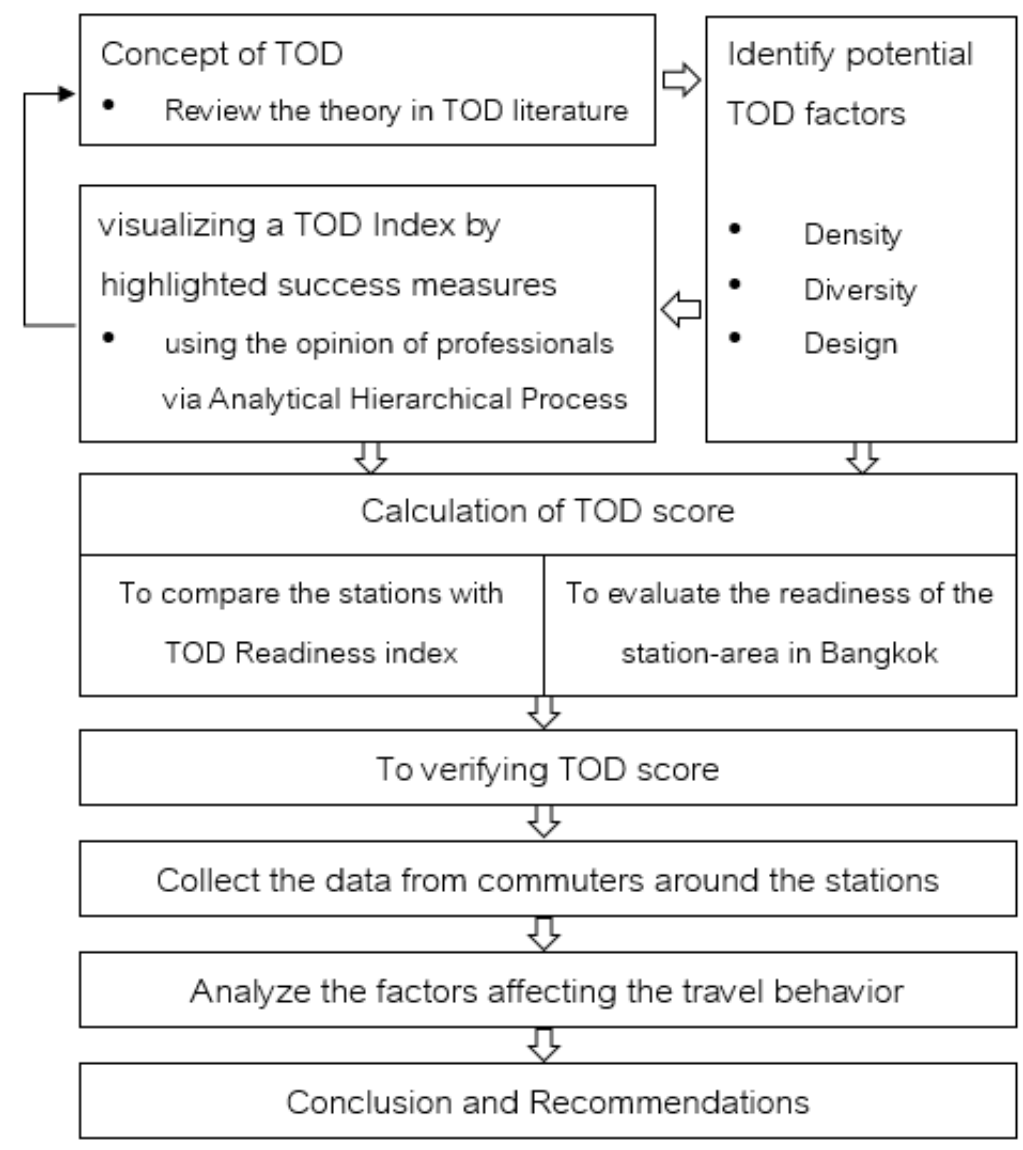

Figure 1. Conceptual framework.

This study of TOD has been cast in the context that promotes the use of public transport while supporting pedestrianfriendliness by threshold the land-use pattern under the measurement of the density, the mixture of the land use pattern around the station area, and the design that is built to support transit commuters. The focus of this study is to measure an area within a 500-meter radius of transit stations using the TOD Readiness Index and evaluating the potential for TOD stations. The results of the TOD Readiness index are expected to be a guideline for establishing the criteria for evaluating any transit station in Bangkok. The concept framework illustrated as followed (Figure. 1).

The objectives are (1) to develop a TOD index and identify the station areas; and (2) to compare the result of potential TOD stations in Bangkok with TOD readiness index, thus the results will include a calculation which will generate a TOD score for each station; and (3) to evaluate the readiness of the station areas in order to promote stations as TOD-compatibles station. Finally, the evaluation will be to verify the TOD stations' score by using multinomial regression to model the travel behaviors from the commuters around the area of transit stations.

\section{Literature review}

TOD is a concept of city development that integrated with a development of transportation infrastructure, especially to focus in the area around the importance transit stations. The TOD concept was introduced and published in the Next American Metropolis (Calthorpe 1993), which is typically defined as compact development within (5-10 minutes) walking distance of transit stations that contains various land use patterns such as housing, jobs, shops, etc. Numerous studies show that in order to achieve an understanding of the context of the TOD station, the heterogeneity of the context of the transit station should be simplified by using a specific evaluation index to create a station typology (Huang et al. 2018; Lyu et al. 2016). There are number of methodologies for evaluating TOD at a station area using existing land use and density information within a given station area; this makes it possible to determine the TOD potential of the selected area (Bertolini 1999; Kamruzzaman et al. 2014; Reusser et al. 2008; Zemp et al. 2011). However, because of station typologies, it is hard to simply adopt a TOD evaluation 
methodology based on an approach done in the past (Zemp et al. 2011). For the index to be effective and accurate, all variables must be measurable. The variables should be diverse and include both development and transit characteristics in a TOD index. Several studies measuring indicator related to transit development; there were few tools to analyze and manage the relation between place and node properties. Regarding the TOD support the use of public transport, Arrington and Cervero (2008) confirmed TOD as the effort to reduce numbers of car usage through mixed land use and high density development complemented by a built environment that supports non-motorized options. Hence, the quality and the design of the transit service also has a major impact on the success potential of TOD (Singh et al. 2014).

\subsection{Factors in transit-oriented development evaluation}

There are few examples where TOD results were quantified to confirm if the study failed or succeeded (Singh et al. 2017). Moreover, urban indicators in built environment as composite index are measured separately and may be unaware of which levels of TOD can be measured. A group of variables, which are Density, Diversity and Design, have become a model variable in the context of the transit-area classification of this study because the variables are commonly used to measure the TOD and have been suggested by various authors for the past decade.

\subsubsection{Density}

The ideal density for the TOD is wide because the degree of density is difficult to define and depends on the compactness of the surrounding area. Density, in general, refers to the degree of compactness of substances, such as people, buildings or services, that are active in a given area or space. According to the literature, Higgins and Kanaroglou (2016) and Guo et al. (2018) defined density, in the context of TOD, as the number or concentration of opportunities per square kilometer, or another surface indicator, such as dwellings, households, people or jobs. Furthermore, TOD density is often categorized by 1) density of the ground area around the station, such as the density of housing, shops, schools, etc., and 2) economic density, such as the number of jobs in the area (Mees 2009). In addition, the density tends to improve public transport through higher potential patronage around each stop. Density, thus, influences the ability to generate and attract trips on the transit network (Higgins and Kanaroglou 2016; Renzaho 2007).

In addition to this study, Density is measured as the total population within 500 meters around a transit station according to the Office of Transport and Traffic Policy and Planning, Ministry of Transport of Thailand.

\subsubsection{Diversity of land use}

In the context of TOD, diversity is usually used in relation to the land use mix or the diversity of housing types. Diversity in TOD will vary according to the area's unique characteristics and the changing dynamics that occur in an urban area over time. According to the literature, there can be many types of diversity in an urban environment, for example: social diversity (different social groups, such as the elderly or low income people), land use diversity, housing diversity, employment diversity, retail diversity, and diversity in the public domain (e.g., streets, plazas and open space). In addition, diversity is used to describe a mix of different uses and the degree of balance between a varied physical design, an expanded public realm, and multiple social groupings of different races, ethnicities, genders, ages, occupations, and households (Lund and Wilson 2005; Lyu et al. 2016; Singh et al. 2017). Diversity, thus, is seen to be achieved where people with different demographic, socio-economic, cultural, employment and visitor characteristics live in an inclusive, interactive and harmonious manner (Pal 2018).

Therefore, in this study, diversity is measured as the total employment and businesses that are located within 500 meters around a station. In addition, the availability of activities and amenities are considered the aspects that underpin successful TOD. This broad mixture is considered to be synonymous with the term 'diversity' for TOD.

\subsubsection{Design}

Design measures in TOD integrate land use, zoning, and transportation planning elements to promote higher-density, mixeduse development that is easily accessible by various modes of transportation through a process of infrastructure modification and construction management. The development of a transit orientation that is designed to decrease the reliance of residents on car ownership includes: carefully articulated land-use mixtures; safe and smooth accessibility to transit stations (enabled by foot paths, cycle paths, and street lights, for example); and amenities such as benches, parks, and landscaping; which all contribute to the development of a good built environment (Pojani and Stead 2015). According to Kong and Pojani (2017), the 
essential characteristics for the design measure in TOD should encourage the transit stations and area around the stations to be residential, and commercial, with employment opportunities that provide proper accessibility for pedestrians, the elderly and people with disabilities, for example, a proper streetscape and walking-friendly footpaths which enhance walkability that attracts pedestrian traffic. These are common fundamental elements of transit-oriented design.

\subsection{Developing indicators}

TOD indicators from this study that have been created are a mathematical combination of a dataset based on statistical principles, according to Wall et al. (1995), who implied that a high level of aggregation is required when confronted with the judgement, such as weighting indicators in order to draw conclusions for possible courses of action (Wall et al. 1995). The indicators present multiple dimensions to each potential transit station to support decision-making, nevertheless to be cautious, the indicators may send misleading messages if they are poorly developed or misinterpreted (Pearce and Atkinson 1993).

\subsubsection{Aggregation techniques for station component calculation}

Each piece of raw data from each station, which are measured in different units, must be converted into the same unit. The following is the equation for calculating the standardized values.

where $f(\min )=a, f(\max )=b$

For this study, $a$ would be the lowest value of the station component and $b$ would be the highest value, for the applied scale range of scores between 0 to 5 of $[\mathrm{min}, \max ]$ into the range $[0,10]$. Therefore, to accept $\min$ into a function in order to get 0 would be as follows:

$$
f(x)=x-\min =0
$$

Meanwhile, to see $\max$, would give $\max$ - $\min$, so the scale would be

$$
f(\min )=0 ; f(\max )=\frac{\max -\min }{\max -\min }=10
$$

Hence, the aggregation can verify that putting in $\min$ for $\mathrm{x}$ now gives $a$, while putting in max gives $b$. Therefore, there is a scaling function that could get any arbitrary values of $a$ and $b$ from any station and its component, as follows:

$$
f(x)=\frac{(b-a)(x-\min )}{\max -\min }+a
$$

This method is more robust when dealing with outliers than a method that takes the average of the percentages around the stations' component mean for each indicator.

\subsubsection{Imitating professional opinions from the literatures by using analytic hierarchical process}

The analytical hierarchy process (AHP) will be applied in this study to helps make simplified decisions on issues that are complicated by mimicking the human decision-making process to derive ratio scales from paired comparisons. AHP is a technique used to divide the elements into sections in the form of hierarchical charts, and then give the weight values for each component using online software (Goepel 2018). By reducing complex decisions to a series of pairwise comparisons, and then synthesizing the results, the AHP helps to capture both subjective and objective aspects of a decision. In addition, the AHP incorporates a useful technique for checking the consistency of the decision maker's evaluations, thus reducing the bias in the decision making process (Salty 1980).

\subsection{Indicators used for transit-oriented development station measurements}

The following tables (Table 1) represent common indicators and measurement variables that are applied for quantification by many researchers (Huang et al. 2018; Kay et al. 2014; Lyu et al. 2016; Pal 2018; Pojani and Stead 2015; Renne and Wells 
Table 1. Common indicators for quantification of context factors

\begin{tabular}{llc}
\hline \multicolumn{1}{c}{ Indicators } & \multicolumn{1}{c}{ Exemplary influences on station-area assessment } & Related context \\
[D1] Population density & Number of the population within a catchment area & Density \\
[D2] Total ridership & Number of commuters for each active station & Density \\
[D3] Employment around transit & Number of jobs within a catchment area & Diversity of land use \\
[D4] Commerce around transit & Number of commercial businesses within a catchment area & Diversity of land use \\
[D5] Walkability & Availability of walkable foot-paths around the station area & Design \\
[D6] Distance to transit station & Estimation of length from an origin to the station & Design \\
[D7] Built environment design & Quality of street crossing improved for pedestrian accessibility to & Design \\
[D8] Station accessibility & station, including ped-shed, lighting around the station area & Design \\
[D9] Station capacity & Basic amenities, commuter safety at the transit station & Design \\
[D10] Parking lots & Availability of the station to connect with other transport modes & Design \\
\hline
\end{tabular}

2005; Singh et al. 2017; Wey et al. 2016; Zemp et al. 2011) in urban transport development for many years since the TOD concept was accepted around the world. The common variables were identified from TOD studies, academic journals and research papers by urban transportation experts. This systematic summary of common indicators was conducted to describe the frequent index that was used for evaluating the area around the transit stations, including other equivalent dimensions in the TOD study.

The Table has described the indicators relevant for the assessment of station areas as identified during the literature review. For indicators, D1-D10 are considered very crucial in achieving an assessment on a potential TOD station and to fulfill the objectives of this study. In Table 1, the criteria that presents the density context are the population around the station area, and also the number of passengers for each active station. Secondly, the contexts describe diversity of land use patterns, such as the number of jobs and businesses that are activated within a catchment area around transit stations. The design contexts describe properties of the design to access transport services at the station, including a holistic quality of streetscape for pedestrian accessibility to the station, as well as safety, basic amenities and the availability of the station to connect with other transport modes.

\subsection{Verify transit-oriented development station using multinomial logistic regression (MLR)}

The logistic regression model is basically the coefficient can be estimated from data that assumed a linear relationship between the predictor variable and the odds of the probability of the event at the station whereas the dependent variable to predict should be categorical data, which is being use for this study in order to verify the TOD score. Therefore, multinomial logistic regression (MLR) is a method that used to predict the probabilities of the discrete outcomes of a dependent variable, by a set of the predictors as the independent variables (Hosmer and Lemeshow 2000) will be a model in the study to verify the TOD station.

An initial step of MLR model was similar to the logistic regression, nonetheless the difference is that dependent variables must be categorical rather than binary, in this case there are 3 possible outcomes of the commuter's decision around the station regarding the travel mode choices; the equation for the probabilities should be as followed:

$$
\hat{\mathrm{Y}}=\frac{e^{u i}}{\sum_{k=1}^{j} e^{u k}}
$$

where; $\hat{Y}$ equals a probability of the event at the station, $u$ equal the parameter of the model, $e$ is the exponential function, $i$ were outcome variable I, and for $j$ represented all dependent variable.

The studies of the relationship between travel behavior and the categorized TOD factor of density, diversity, design, destination accessibility, and distance to transit were found in Ewing \& Cervero's comprehensive review (Ewing and Cervero 2010) and the review was mentioned self-determination may occur without means. Despite the MLR uses a linear predictor function to predict the probability of the outcome variable, the model was able to modelling the choices such as travel mode choice in this case. 
Hence, the MLR framework employed to examined the travel choice behavior is presented in this section. Let $c$ be the index for commuters $(c=1,2, \ldots, C)$ and $i$ be the index for travel choice alternatives $(\mathrm{i}=1,2, \ldots, \mathrm{I})$. With this notation, the formulation takes the following form:

$$
\hat{Y}_{c i}=\alpha^{\prime} \beta_{c i}+\varepsilon_{c i}
$$

The equation, $\hat{Y}_{c i}$ represents the mode selection obtained by the $c$ th commuter in choosing the $i$ th alternative. $\beta_{c i}$ is column vector of attributes affecting the travel mode selection framework. $\alpha$ is a corresponding coefficient column vector of parameters to be estimated, the $\varepsilon_{c i}$ is an error term assumed to be standard type-1 value distributed. Then, the commuter $c$ will select the alternative and the probability expression for choosing alternative $i$ is given by:

$$
\mathrm{P}_{c i}=\frac{\exp \left(\dot{\alpha} \beta_{c i}\right)}{\sum_{j=1}^{i} \exp \left(\dot{\alpha} \beta_{c j}\right)}
$$

The log-likelihood function will be constructed based on the recent probability expression, and maximum likelihood estimation is employed to estimate the parameter $\alpha$.

\section{Data calculation and methods}

This section describes typical indicators that will apply in TOD assessment and evaluations for this study, as well as the method to answer the question on how to develop a TOD index to verify the readiness of a transit station in Bangkok that can improve the features of the transit station to be efficient, in order to promote a station as a TOD-compatible station.

\subsection{Data and measurements}

There are 2 groups of dataset, the dataset for creating TOD index and the dataset of the respondents at the station. Firstly, there are three types of data were used in the process of TOD index: (1) the 2019 census data from The Bangkok Department of City Planning and Urban Development for typology of neighborhood in land use for commercial and residential patterns; (2) spatial datasets to derive the station component of built environment and walkability for commuters from GIS software; and (3) the annual dataset from Bangkok Expressway and Metro to derive the total ridership and the station accessibilities and amenities for the relevant components. Secondly, the 200 respondents were interviewed at the 4 top-scored station regarding their travel basis. The interview was use both conversations and questionnaires to derive the socio-demographic data (i.e., gender, age, and housing genres) and the travel behaviors such as travel cost per month, station usage frequency, and reason to use the station, including the opinion towards the uses of the stations.

\subsubsection{Station component data collection}

The transit stations used for this study are on the "Chaloem Ratchamongkhon Line", of which there is a total distance of approximately 20 kilometers. It is an underground project throughout the line. There are 18 stations which have operated for over 3 years, starting from the front of Hua Lamphong station to the east along Rama IV Road, passing Sam Yan, Lumpini Park and Ratchadaphisek Road. The line then turns left to the north along Ratchadaphisek Road, passing in front of the Queen Sirikit National Convention Center, Asoke intersection, Rama 9 intersection, Huay Kwang intersection, and Ratchada-Ladprao junction. It then turns left along Ladprao Road until Ladprao intersection, and turns left again onto Phaholyothin Road, finishing through Chatuchak Park and straight to the end of the area at Bang Sue railway station. The average distance between stations is 1 kilometer.

To calculate station components, the spatial dataset of 18 transit stations was used for analysis. The catchment area is 500 meters with the transit station at the center. This 500-meters radius represents a suitable 5-10-minute walk for pedestrians and transit commuters. Note that this study includes the building construction for residential and commercial use and the pavement within a 500-meter radius around the station. To predominantly define the station components, the boundaries are according to The Office of Transport and Traffic Policy and Planning (Figure 2). 


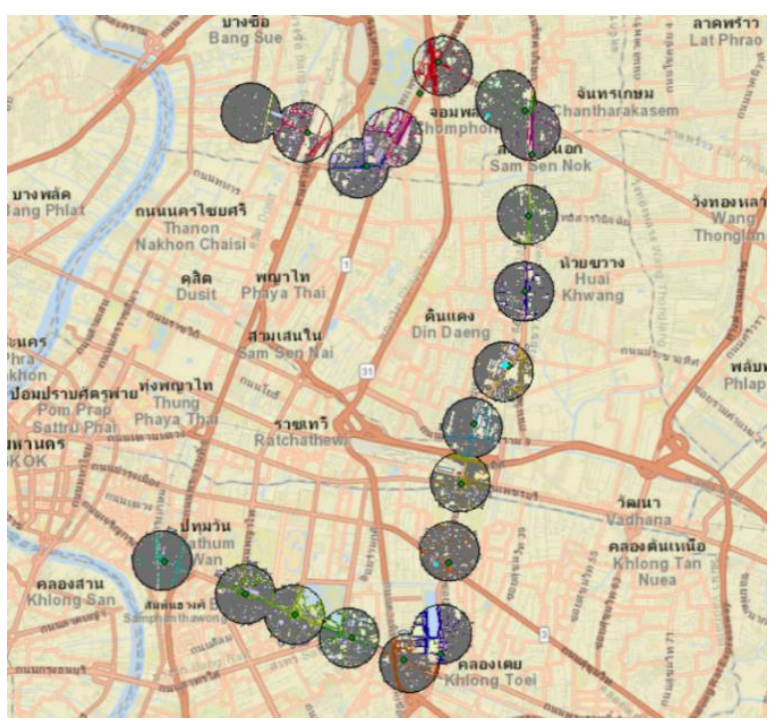

(a)

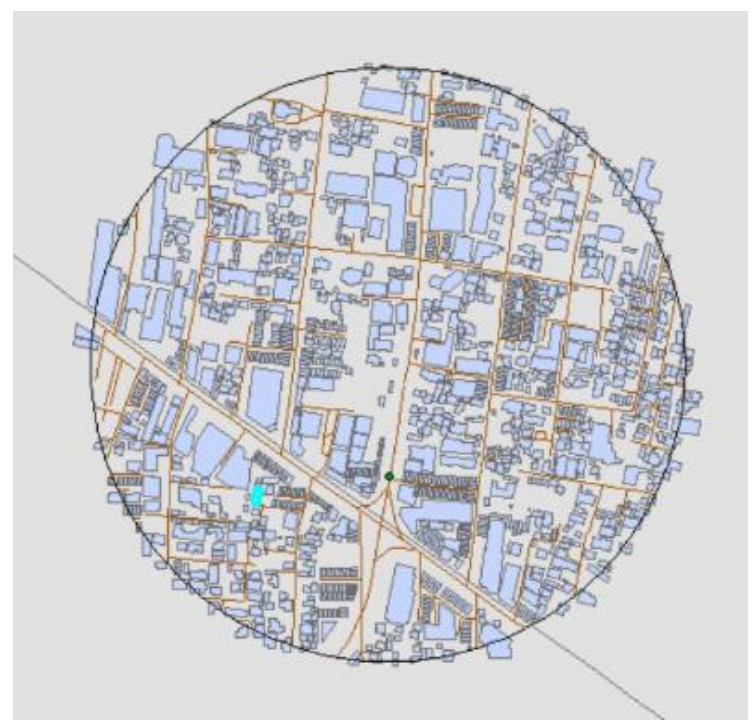

(b)

Figure 2. The transit stations of the study area. (a) Transit stations in Chaloem Ratchamongkhon Line within a 500-meter radius, (b) Example station with catchment of Sukhumvit MRT station in a zoomed view.

\subsubsection{TOD Readiness Indicator Reference Sheet (TRIRS)}

The indicator reference sheet in this study is to use a formation to define characteristics and performance indicators by ensuring data consistency and precise description are correct. In order to promote data quality, the TRIRS is consistent across all activities collecting data for the same indicator within the transit system. The TRIRS can be described as follows (Table 2).

\subsection{Imitated analytical hierarchy process for weighting score}

\subsubsection{Initiation to divergent weight calculation}

The principles of the weight for each station component are according to Saaty's index scale was repeated to address the hierarchy of the index that grouped TOD stations into indicators by the experts' selection. The results from qualified researchers were applied for imitation to the intensity of importance as decision making. This imitation found that the consistency ratio will no longer be an issue because CR is not exceeding 10\% when the experts have found the index to be between 5 to 7 for the measurement of TOD stations. However, the index count shows that using 6 indicators is optimal because the CR will be 0.081 , which is the longest distance to the CR of $10 \%$. The context of Density, Diversity and Design that was revealed in the previous chapter are clearly involved with those D1-D10 components in order to assess the potential for TOD stations. Thus, the initiative method indicated in stating that to have 6 station components instead of all D1 to D10 for weight calculation is the optimal solution (Table 3).

\subsubsection{Convergence weight calculation}

Further, only the weights which have a supreme value from each consistent component $(\mathrm{CR}<10 \%)$ will be selected for further calculation. Concurrently to a duplication of the index characteristics by its description according to the indicator reference sheet (TRIRS), D5 to D6 and D7 until D10 need to merge because they are arguably using the same dataset, and thus can reduce the components, in order to complete the objectives. Hence, the data according to the TRIRS would readjust to make it compatible, as follows (Table 4).

\subsection{Calculating the transit-oriented development readiness score}

Technique that imitates participatory methods of evaluating the weights from the literature is sought; then, a proper weighting system is found, as follows. 
Table 2. Indicator reference sheets for the development of TOD readiness

1. Indicator

Precise definition

Unit of measure Disaggregated by data source

2. Indicator Precise definition

Unit of measure Disaggregated by Data source

3. Indicator Precise definition

Unit of measure Disaggregated by data source

4. Indicator Precise definition

Unit of measure Disaggregated by

Data source

5. Indicator

Precise definition

Unit of measure

Disaggregated by

Data source

6. Indicator

Precise definition

Unit of measure

Disaggregated by

Data source

7. Indicator

Precise definition

Unit of measure

Disaggregated by Data source

8. Indicator

Precise definition

Unit of measure

Disaggregated by

Data source

\section{Population density}

Population was expressed by population density for the area around each of the transit stations within a 500meter radius of the MRT station and reflects the density per square kilometer.

Number of resident units within the catchment area.

Resident/non-resident living in the transit adjacent area, or rural area.

Department of City Planning, Bangkok Office

Total ridership

Total Transit Ridership expressed the number of rides taken by people using the public transit system in a given period of time.

Total number of annual passengers per month at each station on the blue line.

Bangkok Expressway and Metro (BEM) office.

Employment around transit

Employment is described as the amount of job activity around the station area that encompasses occupations in different sectors located around transit stations within the catchment area and reflecting the intensity of employment that brings commuters to the station area.

The employment units are small offices, trading companies, department stores, enterprises, warehouses and wholesalers.

Number of employment sites within 500 meters of the MRT station.

Format of employment conditions for the jobs are not for residential use.

Department of City Planning, Bangkok Office

\section{Commerce around transit}

A variety of businesses were expressed by commercial type in the area around the transit station that encompassed a number of stores, supermarkets, groceries, cafes, laundromats, barbers and pharmacies.

Businesses within the catchment area are used to reflect the variety of business-related land use around transit stations that provides convenient daily needs for people who are mobile around the station area.

Number of businesses within 500 meters of the MRT station.

By the format of the shop building for commercial use, limited to the ground or must not be above a residence. Note** Street food businesses may be excluded for this evaluation.

Department of City Planning, Bangkok Office

Walkability

The extent of availability of walkable pavement which is friendly to the pedestrian measured in total length of foot-paths within a 500-meter radius of the transit station. Meters

Cul-alley $(\mathrm{Y} / \mathrm{N})$

Department of City Planning, Bangkok Office and Google Earth - Maps

Distance to transit station

Distance to transit station expressed the travel duration from the origin to the station entrance. The distance reflects the length between a commuter and a station that can distinguish commuter types.

Travel time duration in minutes

Google Earth - Maps

\section{Built environment design}

Quality of transit station features viewed as a pedestrian support facility, and accessibility to station or nearby landmarks. The design environment includes ped-shed and lighting around the station area.

Proportion of convenient exits per total exits that directly connected to buildings or have weatherproof structures.

Bangkok Expressway and Metro (BEM) office

\section{Station accessibility}

Service levels of a transit station that provides support to commuters with elevators ready to transfer users from the station to the platform.

Supports use for disabled and elderly, or travelers with heavy luggage.

Proportion of elevators per total exits that directly transport the commuters between ground level and the station platform.

Bangkok Expressway and Metro (BEM) office 
Table 2. Continued

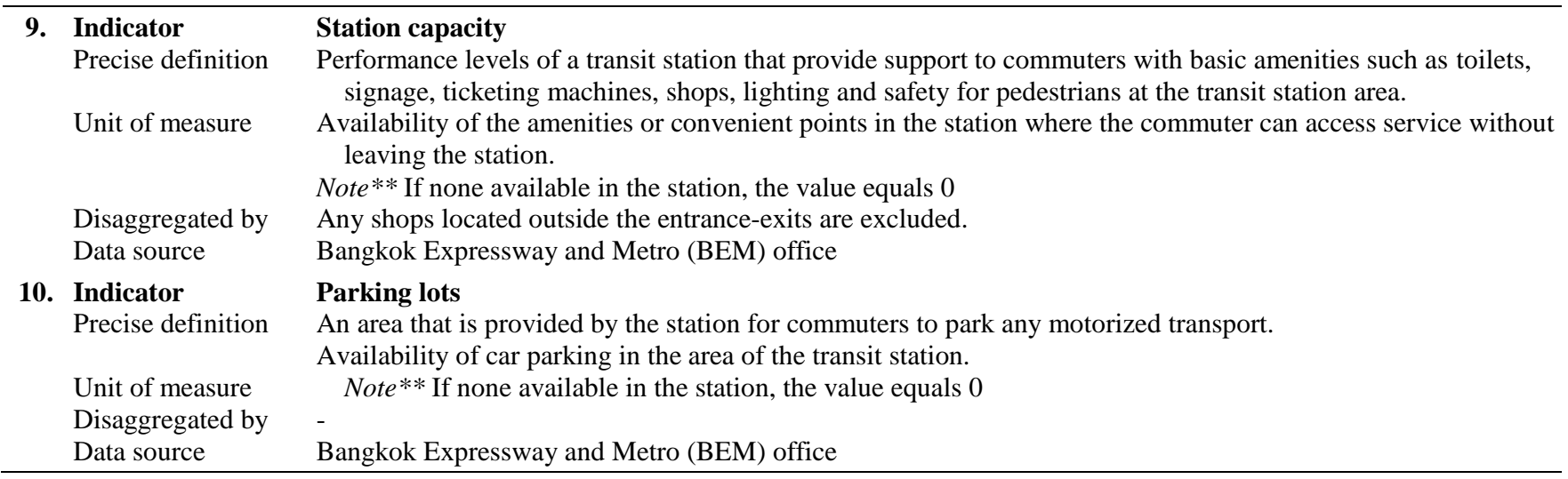

Table 3. The level of importance of each visible indicator of various researchers using imitated analytical hierarchy proces (AHP)

\begin{tabular}{|c|c|c|c|c|c|c|c|c|c|c|}
\hline & I & II & III & IV & V & VI & VII & VIII & IX & $\mathrm{X}$ \\
\hline [D1] $(\%)$ & 26.3 & 29.5 & 7.5 & 31.0 & 16.0 & 29.5 & 26.3 & 16.0 & 17.9 & 28.7 \\
\hline [D2] $(\%)$ & 38.3 & 7.5 & - & - & - & - & - & 26.5 & - & - \\
\hline [D3] (\%) & 17.9 & 44.0 & 25.1 & 22.6 & 11.2 & 15.9 & - & 11.2 & 26.3 & 54.4 \\
\hline [D4] $(\%)$ & - & - & - & - & 6.7 & 7.5 & - & 33.7 & 38.3 & 12.3 \\
\hline [D5] (\%) & 5.1 & - & - & 7.9 & 3.8 & 3.2 & 17.9 & 3.8 & 2.4 & - \\
\hline [D6] (\%) & - & 15.9 & 67.3 & 5.0 & 2.0 & - & 38.3 & - & - & - \\
\hline [D7] $(\%)$ & 10.0 & - & - & 11.1 & - & 44.0 & 5.1 & - & 5.1 & - \\
\hline [D8] (\%) & - & 3.2 & - & 17.7 & 26.5 & - & 2.4 & 6.7 & 10.0 & 4.5 \\
\hline [D9] (\%) & - & - & - & 3.0 & - & - & 10.0 & - & - & - \\
\hline [D10] (\%) & 2.4 & - & - & 1.7 & 33.7 & - & - & 2.0 & - & - \\
\hline Consistency ratio & 0.081 & 0.086 & $\underline{0.170}$ & 0.097 & 0.098 & 0.086 & 0.081 & 0.098 & 0.081 & $\underline{0.111}$ \\
\hline Index count & 6 & 5 & 3 & 8 & 7 & 5 & 6 & 7 & 6 & 4 \\
\hline
\end{tabular}

Note: I. Renne and Wells (2005), II. Zemp et al. (2011), III. Kay et al. (2014), IV. Pojani and Stead (2015), V. Lyu et al. (2016), VI. Wey et al.

(2016), VII. Kong and Pojani (2017), VIII. Singh et al. (2017), IX. Huang et al. (2018), X. Pal (2018).

$\frac{x_{1} w_{1}+x_{2} w_{2}+\ldots+x_{i} w_{i}}{\Sigma w_{i}}=$ TOD Readiness Score

where :

$x_{i}=$ station component score

$w_{i}=$ weight score from imitated AHP

The station component score can be applied after a proper scaling. Equal weighting works well if all sub-indicators are uncorrelated, or they are all highly correlated. This method is based on the standardized scores for each indicator that were captured form the TRIRs, which equal the difference in the indicator (e.g., for each stations' components) divided by the standard error. The range between the minimum and maximum observed standardized scores may vary for each indicator.

The weight score is a weighting method, enables the station component to derive weights as opposed to arbitrarily assigning them. The advantage of using this technique is that the imitated AHP tolerates inconsistency in the way people think through the amount of redundancy. This imitation is analogous to estimating a number by calculating the average of repeated observations. The resulting weights are less sensitive to errors of judgement.

The TOD readiness scores for each stations are tabulated in Table 5. The total lowest and highest ranges of TOD Readiness scores for 18 stations are between 1.393 to 3.507 on a total scale of 1 to 5 . Due to character of the component surrounding the station, the scores for individual criteria such as walkability, station facilities, and employment around the station are considered as high. Thus, it is according to the design components and the diversity of land use criteria's that lead to a production of high total score. The higher TOD readiness score implies that a transit station is more eligible for application of the TOD concept, 
Table 4. Overview of TOD contexts of metro stations in Bangkok

\begin{tabular}{|c|c|c|}
\hline TOD CONTEXT & STATION COMPONENT & MEASUREMENTS \\
\hline \multirow[t]{2}{*}{ DENSITY } & Total ridership & $\begin{array}{l}\text { Total number of rides taken by people using the public transit system for each active } \\
\text { station in a given period of time. }\end{array}$ \\
\hline & Population density & Number of residences within a 500-meter radius around the station. \\
\hline \multirow[t]{2}{*}{ DESIGN } & Station facilities & $\begin{array}{l}\text { The ratio quality of the station amenities, safety for commuters using the services, } \\
\text { including ped-shed and car parking, as well as the availability of the station to connect } \\
\text { with other transport modes. }\end{array}$ \\
\hline & Walkability & $\begin{array}{l}\text { The total availability of walkable pavement within catchment area that supporting } \\
\text { pedestrians to use the transit system and services. }\end{array}$ \\
\hline \multirow[t]{2}{*}{$\begin{array}{l}\text { DIVERSITY OF } \\
\text { LAND USE }\end{array}$} & $\begin{array}{l}\text { Commerce } \\
\text { around station }\end{array}$ & $\begin{array}{l}\text { The number of business types, such as stores, supermarkets, groceries, cafes, laundry, } \\
\text { barbers and pharmacies within the catchment area that encompasses the variety of } \\
\text { business-related land use around transit stations that provides for the daily convenience } \\
\text { needs of people who mobilize around the station area. }\end{array}$ \\
\hline & Employment diversity & $\begin{array}{l}\text { The number of employment sites such as offices, trading companies, department stores, } \\
\text { enterprises, warehouses and wholesalers within the catchment area that encompasses } \\
\text { occupations in different sectors located around transit stations and reflect the intensity } \\
\text { of job employment that brings commuters to the station area. }\end{array}$ \\
\hline
\end{tabular}

Table 5. Results of criteria and TOD readiness score of 18 transit stations

\begin{tabular}{|c|c|c|c|c|c|c|c|}
\hline \multirow[b]{2}{*}{$\begin{array}{l}\text { Station name } \\
\text { (ascended in order } \\
\text { from the score) }\end{array}$} & \multirow[b]{2}{*}{$\begin{array}{l}\text { TOD } \\
\text { readiness } \\
\text { score }\end{array}$} & \multicolumn{6}{|c|}{ Criteria ('w' in each columns represent the weight value of TOD criteria) } \\
\hline & & $\begin{array}{c}\text { Total } \\
\text { ridership } \\
(\mathrm{w}=.099)\end{array}$ & $\begin{array}{c}\text { Population } \\
\text { density } \\
(\mathrm{w}=.062)\end{array}$ & $\begin{array}{c}\text { Station } \\
\text { facilities } \\
(\mathrm{w}=.382)\end{array}$ & $\begin{array}{l}\text { Walkability } \\
(\mathrm{w}=.122)\end{array}$ & $\begin{array}{l}\text { Commerce } \\
\text { around station } \\
(\mathrm{w}=.099)\end{array}$ & $\begin{array}{c}\text { Employment } \\
\text { diversity } \\
(\mathrm{w}=.236)\end{array}$ \\
\hline Hua Lamphong & 3.507 & 1.5 & 5.0 & 2.0 & 5.0 & 5.0 & 5.0 \\
\hline Sam Yan & 3.448 & 1.5 & 1.5 & 3.5 & 4.5 & 5.0 & 3.5 \\
\hline Sukhumvit & 3.426 & 5.0 & 1.5 & 4.5 & 1.5 & 3.5 & 2.5 \\
\hline Phra Ram9 & 3.287 & 3.5 & 3.0 & 4.5 & 3.0 & 2.0 & 2.0 \\
\hline Si Lom & 2.964 & 2.5 & 0.5 & 4.0 & 4.0 & 2.0 & 2.0 \\
\hline Khlong Toei & 2.913 & 0.5 & 2.0 & 4.0 & 5.0 & 2.5 & 1.5 \\
\hline Phetchaburi & 2.725 & 3.0 & 1.0 & 4.5 & 2.0 & 0.5 & 1.5 \\
\hline Phahon Yothin & 2.488 & 2.0 & 1.0 & 3.0 & 4.5 & 3.0 & 1.0 \\
\hline Lat Phrao & 2.367 & 2.0 & 2.5 & 3.0 & 3.0 & 1.5 & 1.5 \\
\hline Chatuchak Park & 2.236 & 3.0 & 0.5 & 3.5 & 2.5 & 1.5 & 0.5 \\
\hline Huai Khwang & 2.233 & 2.0 & 2.5 & 2.0 & 3.0 & 4.0 & 1.5 \\
\hline Kamphaeng Phet & 1.932 & 0.5 & 1.5 & 3.0 & 0.5 & 3.5 & 1.0 \\
\hline Sutthisan & 1.905 & 1.5 & 2.5 & 2.0 & 2.5 & 3.0 & 1.0 \\
\hline Ratchadaphisek & 1.848 & 0.5 & 2.5 & 2.0 & 3.5 & 1.0 & 1.5 \\
\hline Queen Sirikit National Convention Centre & 1.753 & 1.0 & 2.0 & 2.0 & 4.5 & 1.0 & 0.5 \\
\hline Lumphini & 1.480 & 1.5 & 1.0 & 1.5 & 2.0 & 1.0 & 1.5 \\
\hline Thailand Cultural Centre & 1.469 & 3.0 & 1.5 & 1.5 & 1.0 & 1.5 & 1.0 \\
\hline Bang Sue & 1.393 & 0.5 & 1.0 & 2.0 & 1.5 & 1.0 & 1.0 \\
\hline
\end{tabular}

TOD, Transit-Oriented Development.

in order to support pedestrian use of the transit station with less car dependency.

Since, this study of TOD readiness index has been completed to measure 18 station areas for a first instance, there are no reference available from literature. For this reason, the TOD scores were to be compared with each other to promoting the station as a TOD-readiness station, however the case stations with its TOD readiness score must verify into the level of car dependency for the commuters.

To conclude, Figure 3 has illustrated the characteristics for the 4 top scoring stations in a hexagonal diagram. Each diagonal 

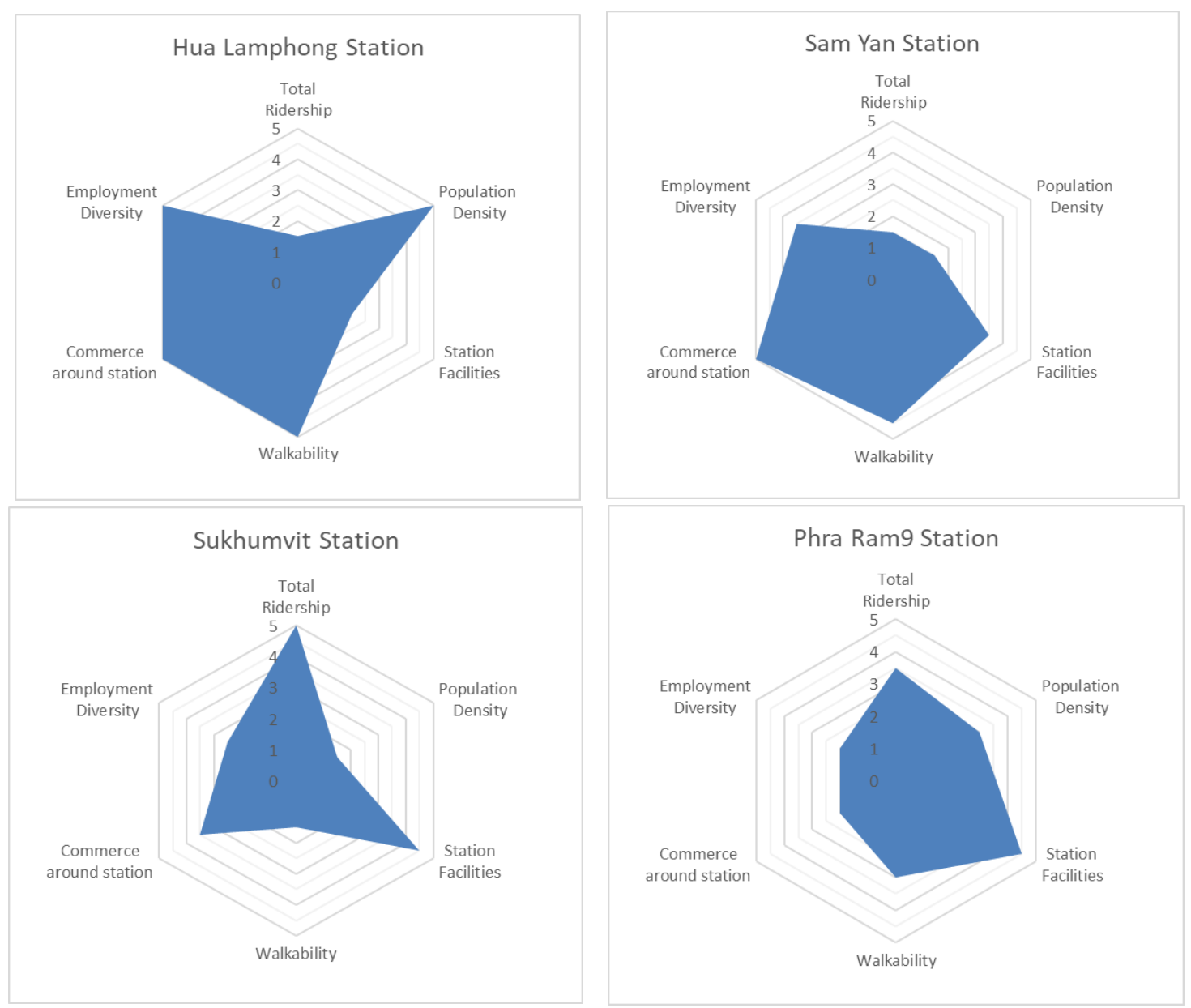

Figure 3. Hexagonal diagrams for the stations that considered high TOD readiness scores. TOD, Transit-Oriented Development.

corner represents the score for each criteria of the station as scaled from 5 to 1 in the same standardized unit. These 4 TODreadiness stations will be verifying.

\section{Analysis and results}

Hua Lamphong station, Sam Yan station, Sukhumvit station, and Phra Ram9 station were selected as the case stations that compatible to TOD station according to the score. The results in this section expected to verifying TOD score for the case stations not only to reduce the car dependency, but to create a reliable TOD development system. Therefore, a study on the development of TOD readiness index for this section will presents the inferential statistics by using MLR model to perform an analysis to identify Factor affecting travel mode selection of the commuters in Bangkok.

\subsection{Factor affecting travel mode selection of the commuters with transit-oriented development readiness index}

The MLR model was used to analyze the travel mode decision of using public transport and using cars from the observation. The analysis was conducted through computerized software package. There are 3 alternative choices for the observation (choices as No, Maybe, or Yes) to identify their selection to using the public transport instead of private vehicle for their travel mobility. The choice will be selected by the respondent as decision, later the travel choice by respondents will be transformed into a nominal data, outcome variable.

\subsubsection{Outcome variables}

A selection of rail mode over car when needed by respondents was used as dependent variable in this study to investigate the 
travel mode selection behavior in order to verify the TOD readiness index along to promote the station as TOD-compatible that support pedestrian friendliness. The respondents were asked to indicate their selection level of the MRT service compared to the car uses when need to commute. There are 3 selection options: No, Maybe, and Yes to decide to use the rail mode services.

The survey gathered across 4 ranked stations to create variable named 'MOREMRT' to indicate their decision to the choice whether choosing the public transport services or the cars when needed as show in the followed Table 6:

In addition, the following Table 7 illustrated correlation co-efficient amongst the demographic and travel behavior variables. The independent variables were applied in the analysis to verify induced travel choice behavior of the commuters, nevertheless the gender variables exhibit no sign of significant. This stage has setting a statistical significance at 0.05 significant level using MLR model. These predictors variable were applied to verify the TOD readiness score encourage the commuters to reduce their car dependency. These predictors variable were applied to verify the TOD readiness score encourage the commuters to reduce their car dependency; for the hypotheses of:

$\mathrm{H}_{0}=$ There is no significant impact in the travel mode selection of the respondent on the station score.

$\mathrm{H}_{1}=$ There is significant impact in the travel mode selection of the respondent on the station score.

\subsubsection{Model fit}

The amount of change between these models suggests a slightly improvement in model fit from the Table 8 . The model fitness was assessing by the chi-square test $(266.48-239.03=27.45)$, and the $p$-value was significance, $\left[\chi^{2}(4)=27.45, p=\right.$ .000]. Using the conventional significant level at .10 thresholds, therefore the group of independent variables (Table 9 and 10) were the significant predictor in the model that are contribute to prediction of the outcome variable. The final model is significantly different from the model without independent variables. Briefly, there is a significant relationship between the predictors and the outcome variables in the final model.

\subsubsection{Effect size}

The model accounts for Mcfadden's 9.9\% to Nagelkerke's 17.1\% of the variance and represents marginally acceptance. However, the likelihood ratio tests illustrated the significance of the predictor computed for each of the independent variables in the Table 8-10. This tests the improvement in the model fit with each of the predictor variables when eliminated, hence those

Table 6. Commuter travel selection between the public transport services and car uses

\begin{tabular}{cccc}
\hline Outcome variable & Classification & Frequency & Percentage $(\%)$ \\
\multirow{2}{*}{ MOREMRT } & No, not to select MRT over car use when needed & 14 & 7.0 \\
& Maybe, to select MRT over car use when needed & 34 & 17.0 \\
& Yes, to select MRT over car use when needed & 152 & 76.0 \\
\hline
\end{tabular}

MLR, multinomial logistic regression.

Table 7. Correlation matrix among the variables

\begin{tabular}{lcccccccc}
\hline & $\mathrm{X}_{1}$ & $\mathrm{X}_{2}$ & $\mathrm{X}_{3}$ & $\mathrm{X}_{4}$ & $\mathrm{X}_{5}$ & $\mathrm{X}_{6}$ & $\mathrm{X}_{7}$ & $\mathrm{X}_{8}$ \\
$\mathrm{X}_{1}$ & - & -.104 & .020 & -.084 & -.127 & -.022 & .131 & .086 \\
$\mathrm{X}_{2}$ & -.104 & - & .051 & -.034 & $-.148^{\mathrm{b}}$ & -.021 & .120 & $.143^{\mathrm{b}}$ \\
$\mathrm{X}_{3}$ & .020 & .051 & - & $-.526^{\mathrm{a}}$ & -.075 & .020 & $.144^{\mathrm{b}}$ & $.151^{\mathrm{b}}$ \\
$\mathrm{X}_{4}$ & -.084 & -.034 & $-.526^{\mathrm{a}}$ & - & $-.163^{\mathrm{b}}$ & .104 & $-.149^{\mathrm{b}}$ & $-.143^{\mathrm{b}}$ \\
$\mathrm{X}_{5}$ & -.127 & $-.148^{\mathrm{b}}$ & -.075 & $-.163^{\mathrm{b}}$ & - & .101 & $-.183^{\mathrm{a}}$ & -.119 \\
$\mathrm{X}_{6}$ & -.022 & -.021 & .020 & .104 & .101 & - & .050 & $.144^{\mathrm{b}}$ \\
$\mathrm{X}_{7}$ & .131 & .120 & $.144^{\mathrm{b}}$ & $-.149^{\mathrm{b}}$ & $-.183^{\mathrm{a}}$ & .050 & $-.144^{\mathrm{b}}$ & $.680^{\mathrm{a}}$ \\
$\mathrm{X}_{8}$ & .086 & $.143^{\mathrm{b}}$ & $.151^{\mathrm{b}}$ & $-.143^{\mathrm{b}}$ & -.119 & $.144^{\mathrm{b}}$ & - & $-680^{\mathrm{a}}$ \\
\hline
\end{tabular}

Note: 1) 'a' and ' $\mathrm{b}$ ' indicates Pearson correlation is significant at the 0.01 and 0.05 level (2-tailed) respectively.

2) $X_{1}=$ gender, $X_{2}=$ age, $X_{3}=$ accommodation types, $X_{4}=$ estimate travel time to station by walk, $X_{5}=$ station score, $X_{6}=$ reason to use the station, $\mathrm{X}_{7}=$ frequency use of the station, $\mathrm{X}_{8}=$ monthly cost of travel by MRT. 
Table 8. Model fitting information

\begin{tabular}{|c|c|c|c|c|c|c|}
\hline \multirow{2}{*}{ Model } & \multicolumn{3}{|c|}{ Model fitting criteria } & \multicolumn{3}{|c|}{ Likelihood ratio tests } \\
\hline & AIC & $\mathrm{BIC}$ & -2 log likelihood & Chi-square & df & Sig. \\
\hline Intercept only & 270.480 & 277.076 & 266.480 & & & \\
\hline Final & 251.029 & 270.819 & 239.029 & 27.450 & 4 & .000 \\
\hline
\end{tabular}

Table 9. Step summary

\begin{tabular}{|c|c|c|c|c|c|c|c|c|}
\hline \multirow{2}{*}{ Model } & \multirow{2}{*}{ Action } & \multirow{2}{*}{ Effect (s) } & \multicolumn{3}{|c|}{ Model fitting criteria } & \multicolumn{3}{|c|}{ Likelihood ration tests } \\
\hline & & & AIC & $\mathrm{BIC}$ & -2 log likelihood & Chi-square $^{2)}$ & $\mathrm{df}$ & Sig. \\
\hline 0 & Entered & $<$ all $>1)$ & 268.580 & 354.337 & 216.580 & . & & \\
\hline 1 & Removed & WALKETA & 264.647 & 343.807 & 216.647 & .067 & 2 & .967 \\
\hline 2 & Removed & WHYMRT & 259.127 & 318.497 & 223.127 & 6.480 & 6 & .372 \\
\hline 3 & Removed & COST & 257.193 & 309.966 & 225.193 & 2.066 & 2 & .356 \\
\hline 4 & Removed & AGE & 256.189 & 302.366 & 228.189 & 2.996 & 2 & .224 \\
\hline 5 & Removed & LIVING & 251.029 & 270.819 & 239.029 & 10.840 & 8 & .211 \\
\hline
\end{tabular}

Stepwise method: Backward Elimination

1) This model contains all effects specified or implied in the MODEL.

2) The chi-square for removal is based on the likelihood ratio test.

\section{Table 10. Likelihood ratio tests}

\begin{tabular}{|c|c|c|c|c|c|c|}
\hline \multirow[b]{2}{*}{ Effect } & \multicolumn{3}{|c|}{ Model fitting criteria } & \multicolumn{3}{|c|}{ Likelihood ration tests } \\
\hline & $\begin{array}{c}\text { AIC of reduced } \\
\text { model }\end{array}$ & $\begin{array}{l}\text { BIC of reduced } \\
\text { model }\end{array}$ & $\begin{array}{l}-2 \text { Log likelihood of } \\
\text { reduced model }\end{array}$ & Chi-square & $\mathrm{df}$ & Sig. \\
\hline Intercept & 253.507 & 266.700 & 245.507 & 6.477 & 2 & .039 \\
\hline SCORE & 252.997 & 266.190 & 244.997 & 5.968 & 2 & .051 \\
\hline FREQUENT & 272.385 & 285.578 & 264.385 & 25.355 & 2 & .000 \\
\hline
\end{tabular}

were being the case for the predictor variables in this study.

\subsubsection{Parameter estimates for the final model}

Despite Table 11 provides result of information comparing each travel selection group against the reference category. The regression coefficient indicate which predictors significantly discriminate between (1) the commuters decided Yes and those who decided No; between (2) the commuter decided Maybe and those who decided No.

(1) The set of coefficient compared between Yes and No groups, the predictor 'score' showed a positive coefficient of 4.230, the exponential beta indicated that the frequent users in 'Yes' group are more likely to choose the MRT services over the car uses up to 68.7 times due to an increase in the TOD score's unit. Secondly, the 'frequent' use was a significant

\section{Table 11. Parameter estimates}

\begin{tabular}{ccrrrrrr}
\hline \multirow{2}{*}{$\begin{array}{c}\text { Select MRT over car when needed } \\
\text { (The reference category is: No) }\end{array}$} & \multicolumn{1}{c}{ B } & Standard error & Wald & Exp. (B) & 95\% Confidence interval for Exp. (B) \\
\cline { 7 - 8 } Maybe & Intercept & 6.530 & 13.064 & .250 & & Lower bound & Upper bound \\
& SCORE & -1.467 & 3.765 & .152 & .231 & .000 & 369.311 \\
& FREQUENT & -.325 & .441 & .545 & .722 & .304 & 1.714 \\
\hline Yes & Intercept & -14.380 & 11.976 & 1.442 & & & \\
& SCORE & 4.230 & 3.439 & 1.513 & 68.707 & .081 & $58,146.691$ \\
& FREQUENT & 1.012 & .407 & 6.195 & 2.751 & 1.240 & 6.105 \\
\hline
\end{tabular}


predictor in the model and coefficient was positive, in addition, the odd ratio indicated that they were likely to using the metro instead of the cars uses up to 2.7 times than usual.

(2) The set of coefficient compared between Maybe and No groups. The score variable as predictor, which the coefficient was negative sign. In addition, the result found the high TOD score affected the commuters by reducing their hesitation in selecting the MRT over car uses by $23 \%$. Finally, the predictor 'frequent' in the model and the coefficient was also negatives. Thus, this indicated that more usages of the MRT can improve the acceptance decision regarding to the use of the MRT services to the commuters who were in the 'Maybe' group by up to $72 \%$ from being hesitate.

\subsubsection{Classification}

The overall model accurately predicted $77.0 \%$ of the cases, however correct classification was only $14.7 \%$ for the 'Maybe' group and no 'No' cases were correctly classified. The prediction on the 'Yes' group of the commuters who select to use the MRT over cars had higher level of accurate prediction at 98.0\% compared to 'Maybe' and 'No' groups. According to Hosmer and Lemeshow (2000), the MLR produced a better prediction to the largest group.

\section{Conclusion and recommendations}

\subsection{Summary of a calculation process to transit-oriented development readiness score}

\subsubsection{The weight score}

The results from imitated AHP technique concluded that there were six attributes to comply with the TOD readiness index. The study in Section 3 insists that having six components to measure is the optimal solution, by reducing duplications on the index that have repeated descriptions, according to the TRIRS. Consequently, the measurement of the distance to transit was combined with walkability, and station accessibility, station capacity and availability of car parking were combined with the built environment design into the station facilities measurement because they were similar in character and were using the same dataset.

The context related to the density for Bangkok's TOD, the total passenger using the station in a given period of time and the number of residences within catchment area account respectively, for the total ridership weight of $9.9 \%$ and the population density weight of $6.2 \%$.

The context related to the design for Bangkok's TOD, total availability of walkable pavement within catchment area for pedestrians to use the station, account for the walkability weight of $12.2 \%$. In addition, the station facilities weight of $38.2 \%$ narrated by the quality of the station amenities that cordially support commuters, includes elderly and disables. The station facilities component consists of elevator units per stations, and the ratio of convenient exits that connect to buildings, and how connected the station is with other transport modes.

The context related to the land-use diversity for Bangkok's TOD, the commerce around station weight of $9.9 \%$ narrated by the variety of commerce that provides for the daily convenience needs of people around the transit stations, the format of the shop building for commercial use must be limited to the ground level or must not be above a residence. The business types include stores, supermarkets, groceries, cafes, laundromats, barbers and pharmacies. However, those street food businesses were not including due to uncertainty about the location and cleanliness issues. In addition, the employment diversity weight of $23.8 \%$ narrated by the intensity of job employment sites that encompasses occupation in different sectors located around transit stations. The building conditions must not be for residential use and open during business hours, such as offices, trading companies, department stores, enterprises, warehouses and wholesalers.

\subsubsection{The stations component score}

The process begins whether acquiring the raw dataset from the Bangkok metro offices authorities for at the stations' integrity and the department of city planning for the land-use patterns. The figures of 4 top-ranked stations were scaled by the equal weighting techniques and presents in hexagonal diagram. The component scores of the station have delivered final scores for a verification in the section 3; Hua Lamphong station (3.507), Samyan station (3.448) and Sukhumvit station (3.426) and Phra Ram9 (3.287) are top scorers and were ranked respectively. However, the low scoring station such as Bang sue (1.393), Thailand cultural centre (1.469), and Lumphini (1.480) stations should be more highly significant improvement when infrastructure development is finished. The areas around these stations are now under construction and it is expected to be finished in 1-2 
years; the TOD scores are expected to be higher than the current scores.

This study was expected to supporting the authorities in which consider creating the TOD zones within 500-meter radius of around the stations, hence allowing Bangkok city to ensures that the TOD policy or plan being prepared is aligned to improve the features of the transit station to be inefficient. TOD planning can be considered to the fact of supporting the use of transit station within walking distance of any MRT stations in Bangkok.

\subsection{Summary of multinomial logistic regression process to the factor affecting the travel choice on transit-}

\section{oriented development-readiness stations}

The dataset contains variable on 200 commuters across the 4 top-ranked stations. The set of independent variables are socio demographic data (i.e., gender, age, and housing genres) and the travel behaviors such as travel cost per month, station usage frequency, and reason to use the station, which the variables contain whether categorical and continuous variable.

The MLR model was used to model nominal outcome variable in this study. The outcome variable was the decisions from the commuter of their travel mode selection between Yes, Maybe, or No to choose the MRT or car uses in which the odds of the outcomes are modeled as a linear combination of the predictor variables. In the MLR process, the model assigns a reference group ('No' group) to which all other levels of the variable ('Yes' and 'Maybe') are compared.

The chi-square ratio test from the fitted model yielded a value of $27.450(\mathrm{p}=0.000)$, indicating a good model fit. Only The station scores and the frequency use of the station are able to predicts the variations on the commuter's decision-making towards the selection of what transport mode they needed for their travel basis. The predictions show that multinomial logistic model was suitable because the model correctly classified $77 \%$ of the total observations. According to Tabatchnick and Fidell (2007), a lower AIC for the final model compared to the intercept model thus suggests good fit, nevertheless marginally acceptance values were obtained for the pseudo- $\mathrm{R}^{2}$ of Nagelkerke: 171, and McFadden: 099.

The limitation of MLR includes the large observations across all level of the outcome variable and the predictor are needed (Hosmer and Lemeshow 2000; Tachibanik and Fedell 2007), the observation numbers were subduing in which an epidemic of the virus spreading leads to many commuters were staying at home thus the sample size was reduced because a frustration in data collecting.

\subsection{Recommendations for the future studies}

The TOD readiness index were formed using a reliable mathematical process by which data on each component of the station are calculated to obtain a result for each station. The design components are the largest weighted among total TOD station scores. This study suggests that future studies on the attitudes (comfortability, convenience, costs, safety, and service reliability) towards station services could also influence transport mode choices. As a result, there is a benefit to investigating the public transport users and whether these attitudes have any impact on the travel choice decisions of regular users or non-frequent users. Another aspect should be on how individuals use public transport at the time of planning and implementation of new station infrastructure. The new station infrastructure policy could be to assess health impacts, such as the walking distances are inputs to health assessment models in order to potentially improving health concerns of living around station issues (Ewing and Cervero 2010). It is importance for the authorities, such as the city planners and the BEM to be aware of commuter attitudes or pedestrian experience regarding the use of walkable pavement and facilities at the area around the station, in order to improve on inefficient features of the transit station. Nonetheless the recent study showed the examinations to loud noise exposure that could affect within the accommodation in TOD area could be the advanced issues when implementing the new potential TOD station (Yildirim and Arefi 2021).

Meanwhile, it is clear that the travel frequency of the stations was associated with travel ticket costs. This study, therefore, suggests that the idea regarding the cost and travel frequency-related decisions of commuters around stations should be taken into account when studying or evaluating new transport infrastructure. The benefits of promotion in monthly ticket fares should also be evaluated. Likewise, the aspect of travel mode choice decisions for the elderly and disabled users should be integrated into urban transport policy when developing new transport infrastructure. More emphasis should be placed on individuals to use the MRT instead of a private car. Otherwise, traffic congestion will continue due to an increase in private transport. Furthemore, Jaafar Sidek et al. (2020) showed that travel characteristics of the commuters influence the TOD station ridership recently, and this could useful for the authorities as hints in which any terms of travel character, such as accommodating type, jobs related, and educations will be found to be the major activities involved at the station area. Another implication for TOD 
policy regards the frequent use of the station could be more rely on the activity such as leisure traveling could also be concerned to an opportunity to increasing the uses for non-regular users. In order to encourage people to use more public transport, an effective public transport policy is required parallel to the assessment of public transport performance measures by the authorities, such as the Bangkok municipality and the Bangkok Expressway and Metro office.

\section{References}

Arrington, G. B., Cervero, R., 2008. Effects of TOD on Housing, Parking, and Travel. Federal Transit Administration., Transit Development Corporation., \& Transit Cooperative Research Program. Washington, D.C.: Transportation Research Board.

Bertolini, L., 1999. Spatial development patterns and public transport: The application of an analytical model in the Netherlands. Planning Practice \& Research 14, 199-210.

Boschmann, E. E., Brady, S. A., 2013. Travel behaviors, sustainable mobility, and transit-oriented developments: A travel counts analysis of older adults in the Denver, Colorado metropolitan area. Journal of Transport Geography 33, 1-11.

Calthorpe, P., 1993. The Next American Metropolis: Ecology, Community, and the American Dream. New York: Princeton Architectural Press.

Ewing, R., Cervero, R., 2010. Travel and the built environment. Journal of the American Planning Association 76, 265-294.

Goepel, K. D., 2018. Implementation of an online software tool for the analytic hierarchy process (AHP-OS). International Journal of the Analytic Hierarchy Process, 10(3), 469-487.

Guo, J., Nakamura, F., Li, Q., \& Zhou, Y., 2018. Efficiency assessment of transit-oriented development by data envelopment analysis: case study on the den-en toshi line in Japan. Journal of Advanced Transportation 2018(2), 1-10.

Higgins, C. D., Kanaroglou, P. S., 2016. A latent class method for classifying and evaluating the performance of station area transit-oriented development in the Toronto region. Journal of Transport Geography 52, 61-72.

Hosmer, D. W., Lemeshow, S., Sturdivant, R. X., 2000. Applied Logistic Regression. In: Hosmer, D. W. Jr. (Ed), Introduction to the Logistic Regression Model. John Wiley \& Sons, New York, NY.

Huang, R., Grigolon, A., Madureira, M., Brussel, M., 2018. Measuring transit-oriented development (TOD) network complementarity based on TOD node typology. The Journal of Transport and Land Use 11, 304-324.

Jaafar Sidek, M. F., Bakri, F. A., Kadar Hamsa, A. A., Aziemah Nik Othman, N. N., Noor, N. M., Ibrahim, M., 2020. Socioeconomic and travel characteristics of transit users at transit-oriented development (TOD) stations. Transportation Research Procedia 48, 1931-1955.

Kamruzzaman, M., Baker, D., Washington, S., Turrell, G., 2014. Advance transit oriented development typology: Case study in Brisbane, Australia. Journal of Transport Geography 34, 54-70.

Kay, A. I., Noland, R. B., \& DiPetrillo, S., 2014. Residential property valuations near transit stations with transit-oriented development. Journal of Transport Geography, 39, 131-140.

Kong, W., \& Pojani, D., 2017. Transit-oriented street design in Beijing. Journal of Urban Design 22, 388-410.

Lund, H. M., Wilson, R. W., 2005. The Pasadena Gold Line: Development Strategies, Location Decisions, and Travel Characteristics along a New Rail Line in the Los Angeles Region. San José State University, San Jose, CA.

Lyu, G., Bertolini, L., Pfeffer, K., 2016. Developing a TOD typology for Beijing metro station areas. Journal of Transport Geography 55, 40-50.

Mees, P., 2009. Transport for Suburbia: Beyond the Automobile Age. Earthscan, Oxfordshire, UK.

Pal, S., 2018. Measuring transit oriented development of existing urban areas around metro stations in Faridabad city. International Journal of Built Environment and Sustainability 5, 115-126.

Pearce, D. W., Atkinson, G. D., 1993. Capital theory and the measurement of sustainable development: An indicator of "weak" sustainability. Ecological Economics 8, 103-108.

Pojani, D., Stead, D., 2015. Transit-oriented design in the Netherlands. Journal of Planning Education and Research 35, 131144.

Renne, J., Voorhees, A., Bloustein, E., \& Jenks, C., 2005. Transit-oriented Development: Developing a Strategy to Measure Success.

Renzaho, A., 2007. Measuring Effectiveness in Humanitarian and Development Aid: Conceptual Frameworks, Principles and Practice. Nova Science Publishers, New York, NY.

Reusser, D. E., Loukopoulos, P., Stauffacher, M., Scholz, R. W., 2008. Classifying railway stations for sustainable transitions - balancing node and place functions. Journal of Transport Geography 16, 191-202. 
Salty, T., 1980. The Analytic Hierarchy Process. McGraw-Hill, New York, NY.

Singh, Y. J., Fard, P., Zuidgeest, M., Brussel, M., van Maarseveen, M., 2014. Measuring transit oriented development: A spatial multi criteria assessment approach for the city region Arnhem and Nijmegen. Journal of Transport Geography 35, 130-143.

Singh, Y. J., Lukman, A., Flacke, J., Zuidgeest, M., Van Maarseveen, M. F. A. M., 2017. Measuring TOD around transit nodes - towards TOD policy. Transport Policy 56, 96-111.

Tabachnick, B., \& Fidell, L. S., 2007. Using Multivarite Statistics (Vol. 3).

Vale, D. S., 2015. Transit-oriented development, integration of land use and transport, and pedestrian accessibility: Combining node-place model with pedestrian shed ratio to evaluate and classify station areas in Lisbon. Journal of Transport Geography $45,70-80$.

Wall, R., Ostertag, K., Block, N., 1995. Synopsis of selected indicator systems for sustainable development. Report for the research project, 'Further development of indicator systems for reporting on the environment' of the Federal Ministry of the Environment. Fraünhofer Institute for Systems and Innovation Research, Karlsruhe.

Wey, W. M., Zhang, H., \& Chang, Y. -J., 2016. Alternative transit-oriented development evaluation in sustainable built environment planning. Habitat International 55, 109-123.

Widyahari, N. L. A., Indradjati, P. N., 2015. The potential of transit-oriented development (TOD) and its opportunity in Bandung metropolitan area. Procedia Environmental Sciences 28, 474-482.

Yildirim, Y., Arefi, M., 2021. How does mixed-use urbanization affect noise? Empirical research on transit-oriented developments (TODs). Habitat International 107, 102297.

Zemp, S., Stauffacher, M., Lang, D. J., Scholz, R. W., 2011. Classifying railway stations for strategic transport and land use planning: Context matters! Journal of Transport Geography 19, 670-679. 